\title{
Promoting mobility and healthy aging in men: a narrative review
}

\author{
P. R. Ebeling ${ }^{1}$ (D) $\cdot$ F. Cicuttini ${ }^{2} \cdot$ D. Scott ${ }^{3} \cdot$ G. Jones $^{4}$
}

Received: 1 March 2019 / Accepted: 2 July 2019 / Published online: 19 July 2019

(C) International Osteoporosis Foundation and National Osteoporosis Foundation 2019

\begin{abstract}
Maintaining mobility is an important aspect of health and well-being in older men. This literature review describes several modifiable and nonmodifiable risk factors impacting bone, muscle, and joint health. Exercise and nutritional interventions may help to prevent the progressive deterioration in bones, muscles, and joints impacting mobility in later life. Limitations in mobility are increasingly recognized as a major public health problem due to an aging population and growing number of older individuals affected by disabling comorbidities. Despite increasing numbers and debilitating consequences, there are no guidelines providing recommendations on strategies to maintain mobility for healthy aging among older men. This narrative review aims to fill this literature gap. PubMed, Scopus, and Google Scholar databases were searched using predefined search terms. Primary studies, exploratory analyses, cross-sectional surveys, meta-analyses, evidence-based clinical reviews, and guidelines from nationally recognized societies focusing on mobility in older men and key elements including bone, muscle and joint health, and balance were selected. Several modifiable and nonmodifiable risk factors have been reported in the literature that impact bone, muscle, and joint health and predispose older men to falls and fractures. The most common conditions impacting bones, muscles, and joints are osteoporosis, sarcopenia, and osteoarthritis, respectively. In addition to being key contributors to disability in the elderly, these conditions are all associated with a higher mortality risk. Although more studies are required, current evidence supports the use of various nonpharmacological (mainly exercise and nutrition) and/or pharmacological treatment modalities to help prevent and/or reverse these conditions. Incorporating lifestyle interventions involving exercise and nutrition at a younger age can help prevent the age-related, progressive deterioration in bones, muscles, and joints that can reduce mobility in later life. Established barriers to physical activities (e.g., poor health, social isolation) in men are important to consider for optimizing outcomes.
\end{abstract}

Keywords Aging $\cdot$ Falls $\cdot$ Male mobility $\cdot$ Osteoporosis $\cdot$ Sarcopenia

\section{Introduction}

Mobility, defined as the ability to move about independently and safely in one's environment, is an important component of health and quality of life among older adults [1]. However, $40 \%$ of individuals reported mobility limitations in a recent

P. R. Ebeling

peter.ebeling@monash.edu

1 School of Clinical Sciences at Monash Health, Monash Medical Centre, Monash University, Level 5 / Block E, 246 Clayton Road, Clayton, VIC 3168, Australia

2 School of Public Health and Preventive Medicine, Monash University, Clayton, VIC, Australia

3 Australian Institute for Musculoskeletal Science, The University of Melbourne, Melbourne, Australia

4 Menzies Institute for Medical Research, University of Tasmania, Hobart, Australia nationally representative survey of insured older adults in the United States (US). The prevalence of mobility limitations assessed as severe or moderate was 21.4 and $18.4 \%$, respectively, among the study sample of 15,989 older adults with Medicare supplemental insurance plans (survey responses were weighted based on demographic, socioeconomic, and clinical variables to adjust for potential bias associated with survey response and stratified sampling to increase generalizability and create a nationally representative study sample) [2]. The authors reported that individuals with mobility limitations were more likely to suffer from depression and less likely to have ambitious goals, resilience, or social support [2].

A previous survey of community-dwelling older adults enrolled in Medicare demonstrated that mobility limitations were common (present in $45 \%$ of the population) and strongly associated with development of future functional disability/ loss of independence and increased healthcare expenditures and utilization [3]. Furthermore, mobility (defined as selfreported ability to walk one-quarter mile) was shown to be an independent predictor of mortality; across the 12- to 16- 
month follow-up period, mortality rates were $15 \%$ for individuals who were unable to walk one-quarter mile at baseline, $4 \%$ for those with mobility difficulty, and $2 \%$ for those with no mobility limitations. This association remained significant even after adjustments were made for multiple confounders including demographics, socioeconomic status, chronic conditions, and health behaviors (difficulty walking one-quarter mile, adjusted odds ratio [OR] 1.57; 95\% CI 1.10-2.24]; inability to walk one-quarter mile, adjusted OR $2.73 ; 95 \%$ CI 1.79-4.15) [3]. Bergland et al. also reported a significant association (hazard ratio [HR] 1.79; 95\% CI 1.33-2.42) between loss of mobility and all-cause mortality in communitydwelling men and women in Norway. This was significant after adjustment for self-reported health, body mass index (BMI), smoking, and education level (HR 1.63; 95\% CI 1.20-2.22) for individuals who were fastest on the timed up and go test of mobility compared with those who were slowest) [1].

\section{Key determinants of male mobility}

Several modifiable and nonmodifiable factors have been reported in the literature that impact bone, muscle, and joint health and can lead to progressive loss of mobility and predispose older men to poor balance, falls, and fractures (Fig. 1) [4-7]. Risk factors shown to influence mobility include older age, lower physical activity, obesity, strength or balance impairment, long-term use of certain medications, history of smoking, excessive alcohol use, nutritional deficiencies, chronic diseases such as obesity, diabetes mellitus, or arthritis, and low socioeconomic status [8-12]. Despite the known benefits of physical activity, exercise-related injuries can lead to mobility limitation, either directly [9] or indirectly via osteoarthritis [10]. Additionally, in men, the gradual decline in serum testosterone concentrations with advancing age is associated with limitations in mobility [13]. Given the importance of mobility and the plethora of risk factors among elderly men, the objective of this narrative review is to describe elements that are vital to healthy aging in men and the modifiable risk factors that need to be managed to maintain a long, productive, and independent life without limitations in mobility [4-7]. Because bone, muscle, and joint health are important modifiable factors that can be relatively easily enhanced to improve mobility, these parameters will be the focus of this review.

\section{Maintenance of bone health}

\section{Prevalence and implications}

A decrease in bone strength (bone mass and bone quality) with a consequent increase in bone fragility and risk of fracture is termed osteoporosis [14], the most common metabolic bone disease in humans [15]. Osteoporosis is associated with an increased risk of minimal trauma fractures of the spine, proximal femur, or distal radius [4]. Osteoporosisrelated fractures, particularly hip fractures, can result in significant mobility disability; among a cohort of hip fracture patients in the US, the proportion of patients able to walk across a room independently decreased from $75 \%$ prefracture to only $15 \% 6$ months post hip fracture [16]. Although more common in women, the prevalence of osteoporosis in men aged $\geq 50$ years is estimated at $4.3 \%$ in the US [17], 6.6\% in Europe [18], and 5.9\% in Australia [19]. Osteoporosis has been categorized as a worldwide epidemic by the International Osteoporosis Foundation (IOF), and prevalence rates are expected to increase dramatically with the aging population in the coming decades, particularly in Asia. Per the IOF estimates, worldwide, one in five men aged over 50 years will experience an osteoporotic fracture [20]. By 2050, the worldwide prevalence of hip fracture is projected to increase by $310 \%$ in men compared with rates in 1990, and more than half of all osteoporotic hip fractures are expected to occur in Asia [21]. Approximately 20 to 25\% of hip fractures occur in men [21]. In a nationwide cohort study of Danish patients, risk of mortality following a hip fracture was found to be substantially higher among men (37.1\%) than women $(26.4 \%)$ in the first 12 months following a hip fracture (male/female risk ratio $1.4 ; p<0.001$ ) [22] Mortality is also higher in men following nonhip minimal trauma fractures [23]. Despite its high prevalence and associated morbidity and increased mortality, osteoporosis in men remains underdiagnosed and undertreated [24].

\section{Risk factors for osteoporosis}

The risk factors associated with osteoporosis are listed in Table 1 [4, 25-27]. Among these, lack of weight-bearing exercise, poor calcium intake, vitamin D deficiency, low or high body weight, cigarette smoking, excessive alcohol use, and long-term use of glucocorticoids are common modifiable risk factors [25]. It is now well established that testosterone, adrenal androgens, estrogen, growth hormone, and insulin-like growth factor-1 decline with advancing age, and this decline has been associated with both reduced bone formation and increased bone loss [28]. Among these, testosterone deficiency and glucocorticoid therapy are the most common secondary risk factors for the development of osteoporosis in men [13].

\section{Management of osteoporosis}

Management of osteoporosis includes lifestyle measures and pharmacologic as well as hormonal therapy [15]. According to the National Osteoporosis Foundation, the universal 
Key Determinants of Male Mobility

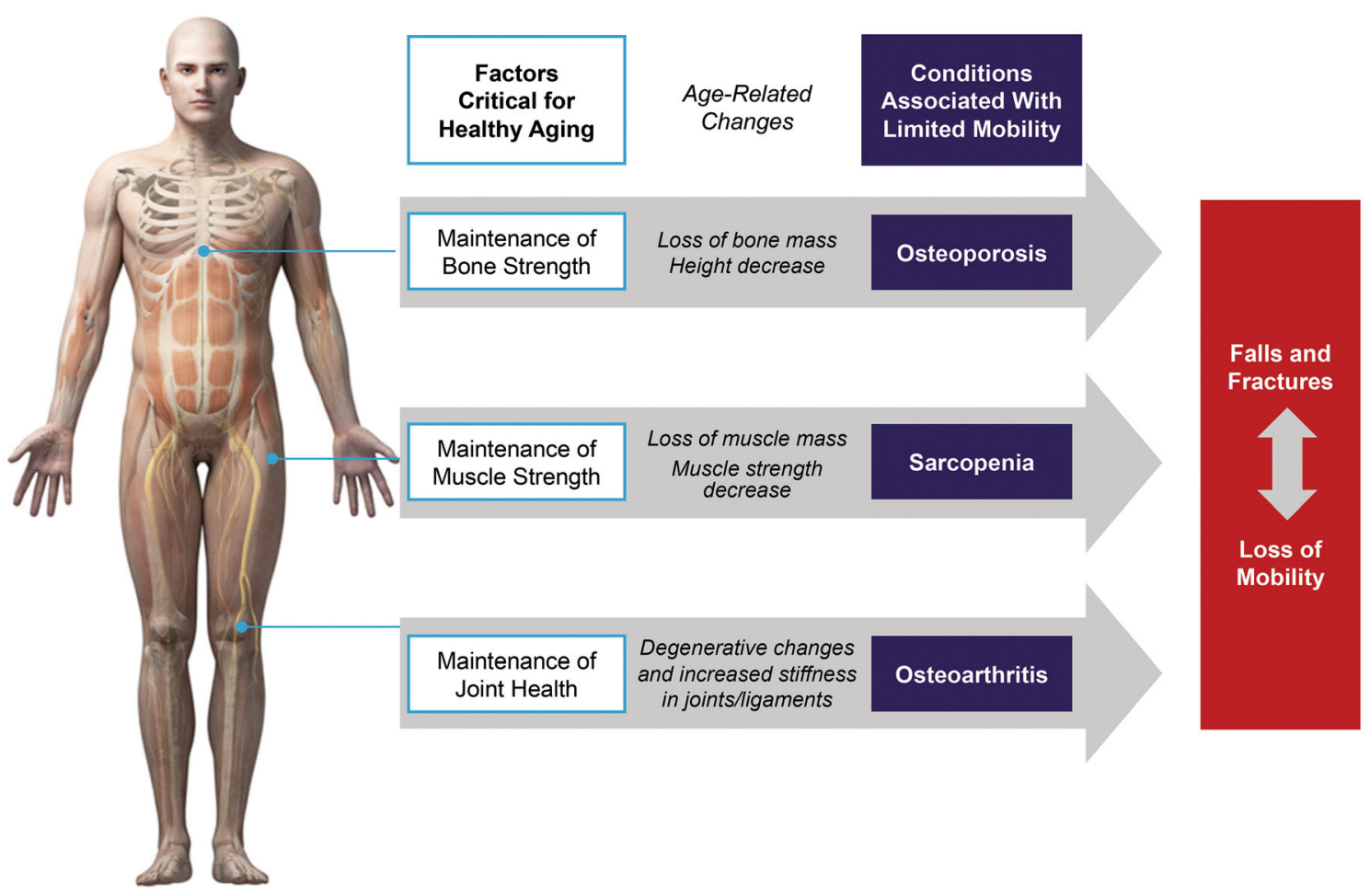

Fig. 1 Key determinants of male mobility [4-7]

recommendations for lifestyle measures include regular weight-bearing and muscle-strengthening exercises, adequate intake of calcium and vitamin D, cessation of tobacco use, avoidance of excessive alcohol consumption, and treatment of risk factors for falling [15]. While the importance of these interventions and the need for supplementation change with age, these lifestyle measures should be maintained throughout life to optimize bone health [25].

Table 1 Risk factors for osteoporosis in men [4, 25-27]

High-risk causes

Medium-risk or infrequent causes
History of nontraumatic fracture (hip, vertebrae, or wrist)

Glucocorticoid use of $5 \mathrm{mg}$ or more per day for $>6$ months

Hypogonadism (glucocorticoid induced or following orchiectomy)

Hyperparathyroidism

Lack of weight-bearing exercise

Poor calcium intake

Vitamin D deficiency

Low or high BMI

Excess alcohol consumption

Tobacco use

Anticonvulsant drug use (phenytoin or phenobarbital)

Rheumatoid or other inflammatory arthritis

Multiple myeloma or lymphoma

Hypothyroidism or hyperthyroidism

Conditions associated with increased risk of falling

(nursing home residence, prior fall, gait disorder, dementia, or hemiparesis)

Family history of osteoporosis

Cushing's disease

Chronic liver or kidney disease

HIV and its treatment

Pernicious anemia

Gastric resection

Mastocytosis

$B M I$, body mass index; $H I V$, human immunodeficiency virus 
A recent systematic review on the effects of exercise on bone mineral density (BMD) [29] found limited positive benefits in controlled clinical trials of exercise training of 6 months or longer in healthy older men (aged $\geq 50$ years) who were not being treated with bone-relevant pharmacologic therapy. Of the six studies the authors identified as relevant for analysis, three studies showed significant improvement in proximal femur BMD, and three found no or inconsistent benefits in the exercise groups. Based on the available literature, the authors concluded that it was not possible to recommend specific exercise interventions for older men that would differ from those based on studies in older women. However, promising effects on lumbar spine BMD have been observed from a highintensity resistance training and impact exercise program in postmenopausal women [30], suggesting higher intensity interventions should be explored in populations at risk of osteoporosis and fracture.

In terms of calcium and vitamin D intake (diet + supplementation), the recommended intakes are 1000-1200 mg of calcium per day and 600-800 IU/day of vitamin D for older men [31,32]. Calcium is required for the mineralization of bone, and the presence of vitamin $\mathrm{D}$ is required for the absorption of dietary calcium in the gut [33]. A meta-analysis based on 8 clinical trials involving 195 hip fracture events and 2231 total fracture events among 30,970 community-dwelling and institutionalized middle-aged to older adults showed a statistically significant $14 \%$ reduction $(95 \%$ CI $0.75-0.98)$ in risk of total fractures and a $39 \%$ reduction (95\% CI 0.46-0.82) in risk of hip fractures with calcium + vitamin D supplementation [33]. A larger reduction in risk was observed in the studies that included institutionalized participants compared with those that involved community-dwelling subjects. Another meta-analysis of studies restricted to communitydwelling adults failed to find a benefit for supplementation with calcium, vitamin D, or the combination [34]. In general, the benefits of calcium and vitamin D supplementation are most consistently evident among older individuals who are institutionalized and other individuals who are vitamin D deficient (serum 25-hydroxyvitamin $\mathrm{D}<50 \mathrm{nmol} / \mathrm{L}$ or $<20 \mathrm{ng} /$ $\mathrm{mL}$ ) [35]. Other analyses have shown that evidence of a benefit is limited to those with baseline 25-hydroxyvitamin D $<30 \mathrm{nmol} / \mathrm{L}$ [36].

For men with clinically recognized osteoporosis (based on fracture history and/or high fracture risk), pharmacologic treatment with bisphosphonates is recommended to reduce the risk of vertebral fracture [37]. Randomized, controlled trials of bisphosphonates in men have mainly been limited to smaller trials examining their effects on BMD as primary study endpoints [38]. However, one trial with intravenous zoledronic acid showed a $67 \%$ reduction in vertebral fractures across a 2-year period as a primary study end point [39]. This class of drugs is approved by the US Food and Drug Administration as a first-line treatment for osteoporosis in men [38]. However, although rare, long-term bisphosphonate use ( $>5$ years) can be associated with osteonecrosis of the jaw, atypical subtrochanteric and diaphyseal femur fractures, atrial fibrillation, and esophageal cancer [40]. Treatment with teriparatide (i.e., recombinant human parathyroid hormone [1-34]), is an option for men with severe osteoporosis at high risk of fracture due to primary or hypogonadal osteoporosis or osteoporosis associated with sustained systemic glucocorticoid use [15]. Although teriparatide was associated with a treatment-dependent increase in the incidence of osteosarcoma in preclinical studies, this has not been observed in humans in postmarketing registries [41]. Nevertheless, the lifetime use of teriparatide is restricted to 18 or 24 months, depending on the country of drug registration [42-44]. Snyder et al. have confirmed a significant positive impact of testosterone therapy on bone density and strength in men with low baseline levels, but larger and longer-duration studies are needed to determine the role of testosterone in fracture prevention [45].

\section{Maintenance of muscle strength}

\section{Definition and prevalence of sarcopenia}

Sarcopenia is broadly defined as the "age-associated loss of skeletal muscle mass and function" [5]. In defining sarcopenia, the Foundation for National Institutes of Health (FNIH) recommended using mobility impairment as the clinically relevant functional state to determine meaningful weakness, and they established an FNIH Sarcopenia Project team to develop a robust and validated clinical definition of sarcopenia [46]. However, there is no clear consensus on the definition of sarcopenia, and several definitions are used, including the recently updated European Working Group on Sarcopenia in Older People (EWGSOP) definition [47], which primarily characterizes sarcopenia as low muscle strength; if low muscle quantity or quality and low physical performance are also present, it is categorized as severe. Sarcopenia has also been defined as "a loss of function, defined by walking speed or distance coupled with a loss of muscle mass" [48]. In 2016, sarcopenia received an ICD-10 code, which represents a major step in recognizing this condition as a disease [49]. In a nationally representative sample of older adults (age $\geq$ 60 years) in the US, the prevalence of sarcopenia among men was $16 \%$ but increased to $28 \%$ when adjusted for BMI [50]. Muscle loss in combination with high levels of adiposity is referred to as sarcopenic obesity [51].

\section{Risks and causes of sarcopenia}

Sarcopenia is associated with increased risk of osteoporosis, falls, fractures, physical disability, functional decline, metabolic syndrome, and hospitalizations [52-54]. An analysis of 
a large prospective cohort of 681 community-dwelling middle-aged and older men and women was performed to determine associations between sarcopenia and risk of falls over 5 years [55]. Results from the analysis indicated variations in the association between sarcopenia and functional decline according to sex; men with low muscle mass had poorer muscle function compared with women [55]. Low muscle mass in older adults with sarcopenia has also been identified as a risk factor for metabolic syndrome and type 2 diabetes. A proposed mechanism is that significantly lower skeletal muscle mass results in greater insulin resistance and consequent type 2 diabetes in older patients with sarcopenia [56]. Sarcopenic men who are obese have even poorer outcomes. In a longitudinal study involving elderly subjects, those with sarcopenic obesity, who were predominantly men, were most likely to experience functional declines, disability, and comorbidities compared with lean sarcopenic or nonsarcopenic obese subjects and those with normal body composition [57]. Similarly, recent data from the Concord Health and Ageing in Men Project (CHAMP) study, a large epidemiologic study of aging in older men ( $\geq 70$ years of age), showed an association between sarcopenic obesity and an increased risk of falls and fractures [58]. Compared with men without sarcopenia or obesity, men with sarcopenic obesity at baseline (defined using the EWGSOP criteria) had significantly higher 2-year fall rates (incidence rate ratio [IRR] 1.66; 95\% CI 1.16-2.37), as did individuals with nonsarcopenic obesity (IRR 1.30; 95\% CI 1.04-1.62) and in those with sarcopenia without obesity (IRR $1.58 ; 95 \%$ CI 1.14-2.17). Although no significant association was found between FNIH-defined sarcopenic obesity and fall rates, there was a significantly increased 6-year fracture rate observed in the FNIH-defined sarcopenic obesity group relative to nonsarcopenic obese men (HR for nonsarcopenic obesity vs sarcopenic obesity 0.44 ; $95 \%$ CI $0.23-0.86$ ).

In addition to sarcopenia being a key contributor to disability in the elderly, individuals with sarcopenia have a 4 times higher risk of mortality [52]. A meta-analysis of 17 prospective studies observed a 4 times higher risk of mortality in individuals with sarcopenia compared with those without sarcopenia [52]. Older men with sarcopenic obesity have been confirmed to have a higher risk of all-cause mortality compared with well-matched controls in a prospective cohort study [51].

The causes of sarcopenia in elderly men are multifactorial and include declines in testosterone concentrations with age, decreased growth hormone, mitochondrial abnormalities, long-term glucocorticoid treatment, elevated proinflammatory cytokines, inactivity, and nutritional deficiencies [59]. It should also be noted that decreases in muscle strength/function are 2-5 times greater than decreases in muscle mass (Fig. 2) [60, 61], and loss of muscle function significantly outpaces loss of muscle mass during aging [62], demonstrating that neuromuscular changes beyond muscle atrophy contribute to functional decline. Indeed, increased fat infiltration of muscle is included in the revised EWGSOP definition as an important component of sarcopenia [47] and a subject we recently reported as being associated with an increased risk for both osteoporosis and falls [63].

\section{Management of sarcopenia}

Exercise, particularly progressive resistance training (PRT), is a well-recognized therapeutic strategy to prevent and reverse sarcopenia. High-velocity PRT is particularly effective at improving lower limb muscle power, a key contributor to mobility [64]. In addition, vitamin $\mathrm{D} /$ calcium and essential amino acid protein supplementation have been shown to have beneficial effects $[65,66]$, although the effects for the latter have been variable across studies [66]. A recent trial suggests that leucine content, rather than total protein content, of supplements may be the primary determinant of myofibrillar protein synthesis [67]. Studies have suggested some additional benefits of combining dietary supplementation with exercise training [52], particularly for protein in conjunction with regular, prolonged PRT ( $\geq 2$ weekly sessions for $\geq 6$ weeks) [68]. Omega-3 fatty acid supplementation has been shown to enhance the effects of PRT for improving strength in older women [69], although this effect has not been demonstrated in older men [70]. Creatinine supplementation combined with resistance training increased lean mass in an elderly cohort in a greater magnitude compared with isolated resistance training in a 12-week, double-blind, randomized, parallel-group, placebo-controlled trial; however, the long-term benefits of this intervention need to be determined [71].

With respect to pharmacological therapy, there are no approved treatments for sarcopenia to date. Testosterone and selective androgen receptor molecules are being used to treat sarcopenia; however, their safety is a concern [59]. Monoclonal antibodies targeting either activin or myostatin, a growth hormone involved in regulating muscle mass and strength, are

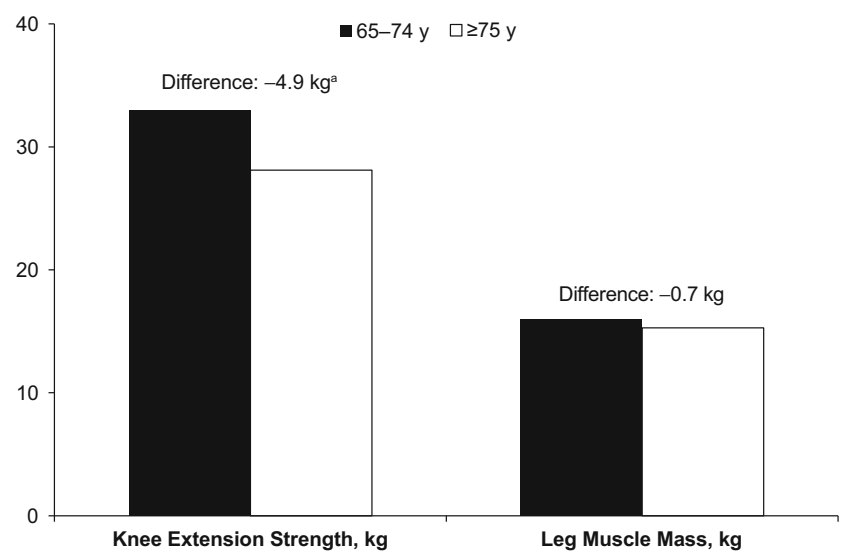

Fig. 2 Comparison of knee extension strength and leg muscle mass in men $65-74$ versus $\geq 75$ years of age [60]. ${ }^{a} p<0.01$ between age groups 
also being investigated as potential agents in the treatment of sarcopenia [72]. One such agent, bimagrumab, an activin type II receptor antagonist, has shown efficacy and safety in increasing skeletal muscle mass and strength in communitydwelling older adults with sarcopenia and mobility limitations and increasing walking speed and mobility in those with lower baseline performance. These data provide strong support for the further evaluation and development of this class of agents [73].

\section{Maintenance of joint health}

\section{Definition and prevalence}

Osteoarthritis is the most common chronic condition affecting the joint that can impact all joint tissues including the cartilage, bone, ligaments, and muscles [74]. The range of joint motion in patients with osteoarthritis is strongly correlated with the level of disability, including walking, sitting, bending, and reclining [75]. In addition to mobility-related disabilities, patients with osteoarthritis suffer with chronic pain, aching, and stiffness and a poor quality of life [76, 77].

In the US, 33\% of men in the age group of 55-64 years have a confirmed diagnosis of arthritis, which increases to almost 50\% in men 85 years of age and older (Fig. 3) [78]. Prevalence rates of arthritis and arthritis-attributable activity limitation are projected to progressively increase through the year 2040, with the largest estimated increases occurring in adults over 65 years of age [78]. When comparing differences in prevalence rates based on gender, osteoarthritis has been shown to affect more men than women aged 50 years; however, following menopause, the rate of osteoarthritis is significantly higher among women, which suggests a sex hormone link in the etiology of the disease $[6,79]$.

\section{Risk factors for osteoarthritis}

Osteoarthritis is a multifactorial disease with a number of modifiable and nonmodifiable risk factors. Modifiable risk factors include obesity, muscle strength, physical activity, improper movements, joint injury, and diet, while nonmodifiable risk factors include age, gender, genetics, ethnicity, and joint and/or bone deformities [6]. Individuals with osteoarthritis have a higher risk of falling, which is augmented by increasing age, pain level, and degree of muscle weakness [80].

\section{Management of osteoarthritis}

Several pharmacologic and nonpharmacologic modalities have been recommended for the management of osteoarthritis. With respect to the nonpharmacologic modalities, the American College of Rheumatology guidelines recommend that patients with knee and hip osteoarthritis enroll in an exercise program that includes aerobic, aquatic, and/or resistance exercises [81]. Additionally, dietary changes have been recommended to prevent or manage symptoms. These include maintaining dietary amounts of essential nutrients from foods and/or supplementing beyond recommended dietary allowances with vitamins $\mathrm{C}$ (ascorbic acid), D (cholecalciferol), $\mathrm{E}$ (tocopherols and tocotrienols), $\mathrm{B}_{3}$ (niacin), $\mathrm{B}_{12}$ (cobalamin), and folate (folic acid, a B vitamin), minerals boron and zinc, essential fatty acids, and some nonessential phytonutrients [82]. As obesity is one of the important modifiable risk factors of osteoarthritis, weight loss by combined diet and exercise is likely to be an effective strategy in overweight or obese patients with osteoarthritis [83].

Pharmacologic treatments for hip and knee OA include adequate pain relief with intermittent dosing of acetaminophen, oral and topical nonsteroidal anti-inflammatory drugs (NSAIDs), tramadol, and intra-articular corticosteroid injections. Intra-articular hyaluronate injections, duloxetine, and opioids are options for individuals not responding to initial therapy; for adults 75 years of age or older, topical rather than oral NSAIDs should be considered in view of the adverse cardiovascular effects associated with NSAIDs [81]. However, all these therapies are, at best, moderately effective, and maintaining a healthy weight and regular exercise remain the most strongly recommended intervention [81-84].

\section{Maintenance of balance}

\section{Prevalence and risk factors}

Loss of balance among older individuals results in falls, which in turn, are associated with fractures, soft tissue injuries, pain, functional impairment, reduced quality of life, hospitalizations, and mortality [7]. According to the US Centers for Disease Control and Prevention, one in four older individuals ( $>65$ years of age) falls each year, and every 19 min, an elderly person dies from a fall [85]. Consequently, falls should be prevented to avoid debilitating consequences among older adults. To prevent falls, it is important to know the risk factors that make an individual prone to falls, and these include vitamin D deficiency, impaired strength and balance, visual impairment, use of multiple prescription medications, solitary living, and environmental hazards such as poor lighting, slippery floors, and uneven surfaces [86]. Pain, a common symptom among older adults, has been associated with problems with balance or coordination, fear of falls, and a history of falls [87]. Therefore, fall prevention programs should incorporate effective pain management strategies [87]. 
Fig. 3 Prevalence of arthritis and attributable activity limitation [78]

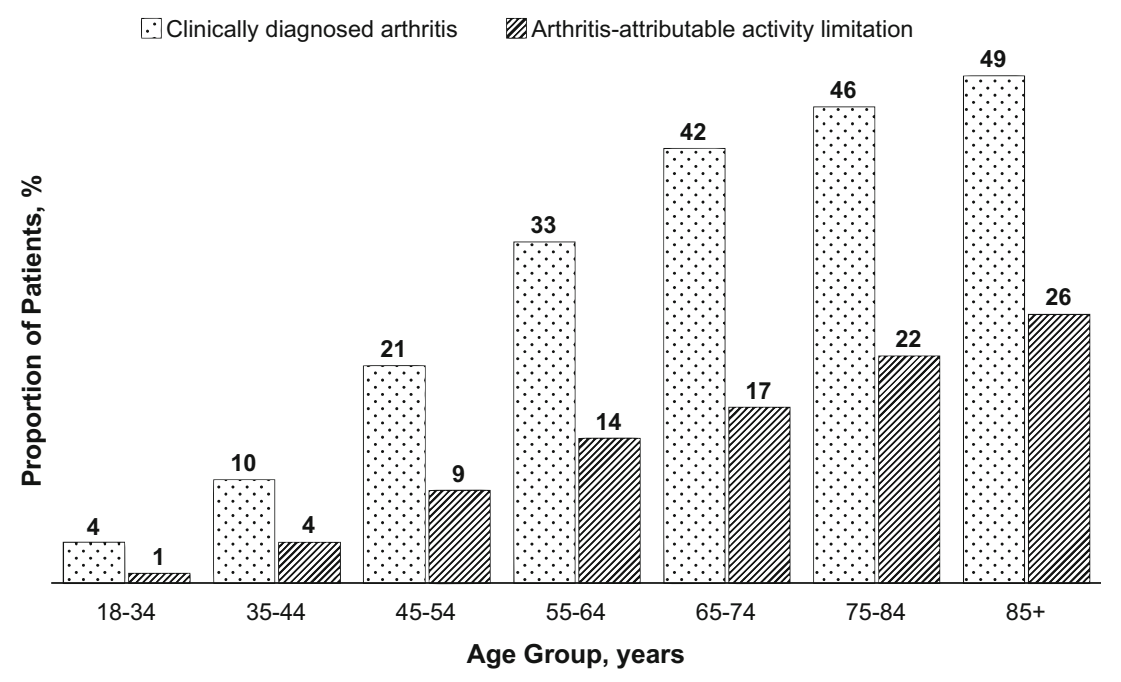

\section{Prevention of falls}

Several structured programs have been reported to be effective in preventing falls. One such primary prevention program, Pennsylvania's Healthy Steps for Older Adults (HSOA), comprises balance assessments, education on falls, and referrals for fall assessments [88]. Completion of the HSOA was associated with a $17 \%$ reduction in falls after adjustment for fall risk factors [88]. The benefits of another approach called the Lifestyle integrated Functional Exercise program, wherein balance and strength activities are taught over five home visits with two booster visits, were assessed in a three-arm, randomized, parallel trial. This study reported a $31 \%$ reduction in the rate of falls compared with a control program [89]. A systematic review and meta-analysis of randomized, controlled trials of exercise as a primary intervention for fall prevention in older adults (mean age $\geq 65$ years) has reported that exercise programs of higher doses $(>3 \mathrm{~h} /$ week) and those that incorporate challenging balance activities are most effective for preventing falls [90]. A recent meta-analysis of 40 randomized, controlled trials of $>20,000$ individuals reported that moderately intensive exercise 2 to 3 times per week significantly decreased the risk of falls and injurious falls but had no effect on fracture risk [91]. Programs that combined balance training and exercise resulted in a $39 \%$ reduction in falls (IRR $0.61 ; 95 \%$ CI $0.53-$ 0.72 ) compared with the $21 \%$ risk reduction found for exercise programs of any type among community-dwelling older adults (pooled rate ratio $0.79 ; 95 \%$ CI $0.73-0.85$ ). The authors found limited evidence available supporting the effect of exercise for fall prevention among older adults living in residential care facilities, after stroke, or following discharge from the hospital [90]. A 9-month study involving members from the University of Connecticut arm of the Frailty and Injuries: Cooperative Studies of Intervention Techniques (FICSIT) trials concluded that a maintenance program of balance and strength exercises might be a more effective strategy to improve balance and strength in older individuals rather than interventions such as Tai Chi, which have shown some benefits in reducing falls, probably by knee and hip strengthening [92].

To recommend suitable interventions that are feasible to implement in primary care for community-dwelling adults over 65 years of age, the US Preventive Services Task Force (USPSTF) published an evidence review and recommendation statement on interventions to prevent falls [93], which was recently updated [94]. This evidence-based guideline recommends exercise interventions (including supervised individual or group classes and physical therapy) to help prevent falls in older adults. The National Council on Aging has further recommended a number of evidence-based fall prevention programs, including Otago, A Matter of Balance, Stay Active and Independent for Life, Stepping On, and Fit \& Strong [95]. Although earlier recommendations included vitamin D supplementation, the benefits to individuals without osteoporosis or vitamin D deficiencies for fall prevention are unclear [94]. As a result, the USPSTF now recommends against vitamin D supplementation for prevention of falls in all community-dwelling older adults. It should be noted that USPSTF regards vitamin D supplementation in subjects with a deficiency as treatment, and these recommendations do not apply to individuals with a diagnosis of osteoporosis or vitamin D deficiency [94]. However, the Endocrine Society and the National Osteoporosis Foundation recommend consumption of fortified foods and/or vitamin D supplements to ensure that recommended intake levels are reached [96, 97]. In addition, a fall prevention program could consider individualizing interventions to address specific risks for each patient, such as the use of anti-slip shoe devices when walking in slippery conditions, monitoring and adjusting psychotropic medications, vision correction, and pacemaker implantation in patients with cardioinhibitory carotid sinus hypersensitivity 
[98]. However, these interventions are supported by limited evidence. The evidence review conducted by the USPSTF found that multifactorial interventions customized to the patient based on an assessment of risk have a small benefit for the prevention of falls, and they recommend that such interventions be selectively offered by clinicians only to those at increased risk for falls [94]. Evidence for medication management and other interventions was too limited or heterogeneous to allow for any definitive conclusions.

\section{Overall clinical recommendations for promoting mobility and healthy aging in men}

Despite the availability of greater socioeconomic facilities and resources, men have a shorter life span than women [99]. Premature mortality among men is often attributed to unhealthy lifestyle choices and lower levels of preventive healthcare $[99,100]$. This combined with the numeric surge in older people presents a critical challenge for public health and highlights the need to specifically improve the health and well-being of older men [100]. In this review, we have focused on discussing various conditions that commonly cause limitations in mobility among older men, including osteoporosis, sarcopenia, osteoarthritis, and balance.

Bone health can be improved by taking relatively simple preventive actions throughout the life span [25]. Preventive care should focus on regular weight-bearing and musclestrengthening exercises; adequate intake of protein, calcium, and vitamin $\mathrm{D}$; maintaining a healthy weight; cessation of tobacco use; avoidance of excessive alcohol consumption; and treatment of risk factors for falling [15]. While the importance of these interventions and the need for supplementation change with age, these lifestyle measures should be maintained throughout life to optimize bone health [25].

Men with strong masculinity beliefs are less likely to receive preventive care [99] and often have difficulty talking about their health problems when they occur, which frequently serves as a barrier to help-seeking behavior [101]. Poor health has been shown to be one of the most important barriers to participating in physical activity, in particular for older men ( $\geq 80$ years) [102]. For men in particular, aches and pains, which are frequent consequences of physical activity, are often a barrier to further physical activity for men who start these activities aggressively and subsequently become disincentivized to participate. Additionally, social isolation is common among older men, particularly among those who experience mood or cognitive problems or who live alone [100], which has been shown to be an independent risk factor for not participating in physical activities [102]. Potential motivators for physical activity include task-related factors, such as meaningful, enjoyable, and routine activities to participate in; individual-level factors, including a group of peers as well as younger friends; and environmental factors such as places to rest and family support [101]. A recent study reported that older adults should receive adequate background information about the rationale for performing physical exercise and clarification that an exercise program will be safe and provide benefits to various aspects of their lives, including mobility, independence, and quality of life, and will not do harm [103].

Considering the benefits of engaging in community programs and men's relatively lower rate of involvement, there is a strong need to develop community programs that target older men in particular, such as "Men's Sheds" [100]. This program originated in Australia to create a positive impact on social engagement, adult education, and health and has now expanded to several other countries globally, enabling men to socialize and participate in learning activities. Such programs should be made available to all older men and should include educational programs and lifestyle interventions to support desirable lifestyle behaviors at all stages of life in healthy individuals [104].

\section{Summary}

Age-related changes in bones, muscles, and joints, as well as declines in balance, can impact mobility in older men. There needs to be a coordinated approach among healthcare providers, who should work closely with older men and/or their caregivers to provide and re-evaluate evidence-based and effective interventions to optimize bone, muscle, and joint health. This is required to maintain strength, balance, and flexibility, which are essential for independent mobility, a key component of healthy aging. Additionally, interventions involving exercise and nutrition, and specifically supporting participation in men, should be initiated as early as possible to prevent and/or reverse the progressive deterioration in bone, muscle, and joint health with aging and, subsequently, to delay the onset of these common and chronic diseases that limit mobility and prevent healthy aging. Barriers specific to males have been identified, including a tendency to have difficulty discussing health-related concerns, and these should be the focus of interventions to engage men in health-promoting behaviors that are relevant to improving bone, muscle, and joint health.

Acknowledgments Medical writing support was provided by Diane Sloan, PharmD, of Peloton Advantage, LLC, an OPEN Health company

Funding information Medical writing support was funded by an unrestricted educational grant from Pfizer. 


\section{Compliance with ethical standards}

Conflict of interest PRE has received research funding from Alexion, Amgen, and Eli Lilly and speaker honoraria from Amgen. FC declares that she has no conflict of interest. DS has received a speaker honorarium from Amgen. GJ declares that he has no conflict of interest.

\section{References}

1. Bergland A, Jorgensen L, Emaus N, Strand BH (2017) Mobility as a predictor of all-cause mortality in older men and women: 11.8 year follow-up in the Tromso study. BMC Health Serv Res 17:22. https://doi.org/10.1186/s12913-016-1950-0

2. Musich S, Wang SS, Ruiz J, Hawkins K, Wicker E (2018) The impact of mobility limitations on health outcomes among older adults. Geriatr Nurs 39:162-169. https://doi.org/10.1016/j. gerinurse.2017.08.002

3. Hardy SE, Kang Y, Studenski SA, Degenholtz HB (2011) Ability to walk $1 / 4$ mile predicts subsequent disability, mortality, and health care costs. J Gen Intern Med 26:130-135. https://doi.org/ 10.1007/s11606-010-1543-2

4. Campion JM, Maricic MJ (2003) Osteoporosis in men. Am Fam Physician 67:1521-1526

5. Fielding RA, Vellas B, Evans WJ, Bhasin S, Morley JE, Newman AB, Abellan van Kan G, Andrieu S, Bauer J, Breuille D, Cederholm T, Chandler J, de Meynard C, Donini L, Harris T, Kannt A, Keime Guibert F, onder G, Papanicolaou D, Rolland Y, Rooks D, Sieber C, Souhami E, Verlaan S, Zamboni M (2011) Sarcopenia: an undiagnosed condition in older adults. Current consensus definition: prevalence, etiology, and consequences. International Working Group on Sarcopenia. J Am Med Dir Assoc 12:249-256. https://doi.org/10.1016/j.jamda. 2011.01.003

6. Musumeci G, Aiello FC, Szychlinska MA, Di Rosa M, Castrogiovanni P, Mobasheri A (2015) Osteoarthritis in the XXIst century: risk factors and behaviours that influence disease onset and progression. Int J Mol Sci 16:6093-6112. https://doi. org/10.3390/ijms16036093

7. Sanders KM, Lim K, Stuart AL, Macleod A, Scott D, Nicholson GC, Busija L (2017) Diversity in fall characteristics hampers effective prevention: the precipitants, the environment, the fall and the injury. Osteoporos Int 28:3005-3015. https://doi.org/10.1007/ s00198-017-4145-6

8. Brown CJ, Flood KL (2013) Mobility limitation in the older patient: a clinical review. JAMA 310:1168-1177. https://doi.org/10. 1001/jama.2013.276566

9. Iezzoni LI, McCarthy EP, Davis RB, Siebens H (2001) Mobility difficulties are not only a problem of old age. J Gen Intern Med 16: 235-243

10. Guccione AA, Felson DT, Anderson JJ, Anthony JM, Zhang Y, Wilson PW, Kelly-Hayes M, Wolf PA, Kreger BE, Kannel WB (1994) The effects of specific medical conditions on the functional limitations of elders in the Framingham Study. Am J Public Health 84:351-358

11. Vincent HK, Vincent KR, Lamb KM (2010) Obesity and mobility disability in the older adult. Obes Rev 11:568-579. https://doi.org/ 10.1111/j.1467-789X.2009.00703.x

12. Yeom HA, Fleury J, Keller C (2008) Risk factors for mobility limitation in community-dwelling older adults: a social ecological perspective. Geriatr Nurs 29:133-140. https://doi.org/10.1016/j. gerinurse.2007.07.002
13. Ebeling PR (2010) Androgens and osteoporosis. Curr Opin Endocrinol Diabetes Obes 17:284-292. https://doi.org/10.1097/ MED.0b013e328339658c

14. Compston J, Cooper A, Cooper C et al (2017) UK clinical guideline for the prevention and treatment of osteoporosis. Arch Osteoporos 12:43. https://doi.org/10.1007/s11657-017-0324-5

15. Cosman F, de Beur SJ, LeBoff MS, Lewiecki EM, Tanner B, Randall S, Lindsay R (2014) Clinician's guide to prevention and treatment of osteoporosis. Osteoporos Int 25:2359-2381. https:// doi.org/10.1007/s00198-014-2794-2

16. Marottoli RA, Berkman LF, Cooney LM Jr (1992) Decline in physical function following hip fracture. J Am Geriatr Soc 40: 861-866

17. Wright NC, Looker AC, Saag KG, Curtis JR, Delzell ES, Randall S, Dawson-Hughes B (2014) The recent prevalence of osteoporosis and low bone mass in the United States based on bone mineral density at the femoral neck or lumbar spine. J Bone Miner Res 29: 2520-2526. https://doi.org/10.1002/jbmr.2269

18. Hernlund E, Svedbom A, Ivergard M, Compston J, Cooper C, Stenmark J, McCloskey EV, Jonsson B, Kanis JA (2013) Osteoporosis in the European Union: medical management, epidemiology and economic burden. A report prepared in collaboration with the International Osteoporosis Foundation (IOF) and the European Federation of Pharmaceutical Industry Associations (EFPIA). Arch Osteoporos 8:136. https://doi.org/10.1007/ s11657-013-0136-1

19. Henry MJ, Pasco JA, Nicholson GC, Kotowicz MA (2011) Prevalence of osteoporosis in Australian men and women: Geelong Osteoporosis Study. Med J Aust 195:321-322

20. (2014) The global burden of osteoporosis: a factsheet. International Osteoporosis Foundation. https://www. iofbonehealth.org/sites/default/files/media/PDFs/Fact\%20Sheets/ 2014-factsheet-osteoporosis-A4.pdf. Accessed 12 Feb 2019

21. International Osteoporosis Foundation (2017) Osteoporosis facts and statistics. International Osteoporosis Foundation. https:// www.iofbonehealth.org/facts-statistics. Accessed 12 Feb 2019

22. Kannegaard PN, van der Mark S, Eiken P, Abrahamsen B (2010) Excess mortality in men compared with women following a hip fracture. National analysis of comedications, comorbidity and survival. Age Ageing 39:203-209. https://oi.org/10.1093/ageing/ afp221

23. Chen W, Simpson JM, March LM, Blyth FM, Bliuc D, Tran T, Nguyen TV, Eisman JA, Center JR (2018) Comorbidities only account for a small proportion of excess mortality after fracture: a record linkage study of individual fracture types. J Bone Miner Res 33:795-802. https://doi.org/10.1002/jbmr.3374

24. Feldstein AC, Nichols G, Orwoll E, Elmer PJ, Smith DH, Herson M, Aickin M (2005) The near absence of osteoporosis treatment in older men with fractures. Osteoporos Int 16:953-962. https://doi. org/10.1007/s00198-005-1950-0

25. Ebeling PR, Daly RM, Kerr DA, Kimlin MG (2013) Building healthy bones throughout life: an evidence-informed strategy to prevent osteoporosis in Australia. Med J Aust 199:S1

26. (2018) HIV and osteoporosis. US Department of Health and Human Services. https://aidsinfo.nih.gov/understanding-hiv-aids/ fact-sheets/22/62/hiv-and-osteoporosis. Accessed 12 Feb 2019

27. Rossini M, Zanotti R, Viapiana O, Tripi G, Orsolini G, Idolazzi L, Bonadonna P, Schena D, Escribano L, Adami S, Gatti D (2014) Bone involvement and osteoporosis in mastocytosis. Immunol Allergy Clin N Am 34:383-396. https://doi.org/10.1016/j.iac. 2014.01.011

28. Seeman E (1999) Osteoporosis in men. Osteoporos Int 9(Suppl 2): S97-s110

29. Kemmler W, Shojaa M, Kohl M, von Stengel S (2018) Exercise effects on bone mineral density in older men: a systematic review 
with special emphasis on study interventions. Osteoporos Int 29: 1493-1504. https://doi.org/10.1007/s00198-018-4482-0

30. Watson SL, Weeks BK, Weis LJ, Harding AT, Horan SA, Beck BR (2018) High-intensity resistance and impact training improves bone mineral density and physical function in postmenopausal women with osteopenia and osteoporosis: the LIFTMOR randomized controlled trial. J Bone Miner Res 33:211-220. https://doi. org/10.1002/jbmr.3284

31. National Institute of Health (2016) Calcium fact sheet for health professionals. National Institute of Health Office of Dietary Supplements. https://ods.od.nih.gov/factsheets/CalciumHealthProfessional/. Accessed 12 Feb 2019

32. (2016) Vitamin D fact sheet for health professionals. National Institutes of Health. https://ods.od.nih.gov/factsheets/VitaminDHealthProfessional/. Accessed 12 Feb 2019

33. Weaver CM, Alexander DD, Boushey CJ, Dawson-Hughes B, Lappe JM, LeBoff MS, Liu S, Looker AC, Wallace TC, Wang DD (2016) Calcium plus vitamin D supplementation and risk of fractures: an updated meta-analysis from the National Osteoporosis Foundation [published erratum and additional analyses appear in Osteoporos Int. 2016;27(8):2643-2646]. Osteoporos Int 27:367-376. https://doi.org/10.1007/s00198-0153386-5

34. Zhao JG, Zeng XT, Wang J, Liu L (2017) Association between calcium or vitamin D supplementation and fracture incidence in community-dwelling older adults: a systematic review and metaanalysis. JAMA 318:2466-2482. https://doi.org/10.1001/jama. 2017.19344

35. Lips P, Gielen E, van Schoor NM (2014) Vitamin D supplements with or without calcium to prevent fractures. Bonekey Rep 3:512. https://doi.org/10.1038/bonekey.2014.7

36. Macdonald HM, Reid IR, Gamble GD, Fraser WD, Tang JC, Wood AD (2018) 25-Hydroxyvitamin D threshold for the effects of vitamin D supplements on bone density: secondary analysis of a randomized controlled trial. J Bone Miner Res 33:1464-1469. https://doi.org/10.1002/jbmr.3442

37. Qaseem A, Forciea MA, McLean RM, Denberg TD (2017) Treatment of low bone density or osteoporosis to prevent fractures in men and women: a clinical practice guideline update from the American College of Physicians. Ann Intern Med 166:818-839. https://doi.org/10.7326/m15-1361

38. Sim LW, Ebeling PR (2013) Treatment of osteoporosis in men with bisphosphonates: rationale and latest evidence. Ther Adv Musculoskelet Dis 5:259-267. https://doi.org/10.1177/ 1759720x13500861

39. Boonen S, Reginster JY, Kaufman JM, Lippuner K, Zanchetta J, Langdahl B, Rizzoli R, Lipschitz S, Dimai HP, Witvrouw R, Eriksen E, Brixen K, Russo L, Claessens F, Papanastasiou P, Antunez O, Su G, Bucci-Rechtweg C, Hruska J, Incera E, Vanderschueren D, Orwoll E (2012) Fracture risk and zoledronic acid therapy in men with osteoporosis. N Engl J Med 367:1714 1723. https://doi.org/10.1056/NEJMoa1204061

40. Brown JP, Morin S, Leslie W, Papaioannou A, Cheung AM, Davison KS, Goltzman D, Hanley DA, Hodsman A, Josse R, Jovaisas A, Juby A, Kaiser S, Karaplis A, Kendler D, Khan A, Ngui D, Olszynski W, Ste-Marie LG, Adachi J (2014) Bisphosphonates for treatment of osteoporosis: expected benefits, potential harms, and drug holidays. Can Fam Physician 60:324 333

41. Andrews EB, Gilsenan AW, Midkiff K, Sherrill B, Wu Y, Mann BH, Masica D (2012) The US postmarketing surveillance study of adult osteosarcoma and teriparatide: study design and findings from the first 7 years. J Bone Miner Res 27:2429-2437. https:// doi.org/10.1002/jbmr.1768

42. (2017) Forsteo [summary of product characteristics]. Eli Lilly Nederland, Utrecht, The Netherlands
43. (2016) Forteo [package insert]. Eli Lilly and Company, Indianapolis, IN

44. (2015) Forteo AU [package insert]. Eli Lilly Australia Pty Limited, West Ryde, NSW, Australia

45. Snyder PJ, Kopperdahl DL, Stephens-Shields AJ, Ellenberg SS, Cauley JA, Ensrud KE, Lewis CE, Barrett-Connor E, Schwartz AV, Lee DC, Bhasin S, Cunningham GR, Gill TM, Matsumoto AM, Swerdloff RS, Basaria S, Diem SJ, Wang C, Hou X, Cifelli D, Dougar D, Zeldow B, Bauer DC, Keaveny TM (2017) Effect of testosterone treatment on volumetric bone density and strength in older men with low testosterone: a controlled clinical trial. JAMA Intern Med 177:471-479. https://doi.org/10.1001/jamainternmed. 2016.9539

46. Studenski SA, Peters KW, Alley DE, Cawthon PM, McLean RR, Harris TB, Ferrucci L, Guralnik JM, Fragala MS, Kenny AM, Kiel DP, Kritchevsky SB, Shardell MD, Dam TTL, Vassileva MT (2014) The FNIH sarcopenia project: rationale, study description, conference recommendations, and final estimates. J Gerontol A Biol Sci Med Sci 69:547-558. https://doi.org/10.1093/gerona/ glu010

47. Cruz-Jentoft AJ, Bahat G, Bauer J, Boirie Y, Bruyère O, Cederholm T, Cooper C, Landi F, Rolland Y, Sayer AA, Schneider SM, Sieber CC, Topinkova E, Vandewoude M, Visser M, Zamboni M, Writing Group for the European Working Group on Sarcopenia in Older People 2 (EWGSOP2), and the Extended Group for EWGSOP2, Bautmans I, Baeyens JP, Cesari M, Cherubini A, Kanis J, Maggio M, Martin F, Michel JP, Pitkala K, Reginster JY, Rizzoli R, Sánchez-Rodríguez D, Schols J (2019) Sarcopenia: revised European consensus on definition and diagnosis. Age Ageing 48:16-31. https://doi.org/10.1093/ ageing/afy 169

48. Morley JE, von Haehling S, Anker SD (2014) Are we closer to having drugs to treat muscle wasting disease? J Cachexia Sarcopenia Muscle 5:83-87. https://doi.org/10.1007/s13539014-0149-7

49. Cao L, Morley JE (2016) Sarcopenia is recognized as an independent condition by an International Classification of Disease, tenth revision, clinical modification (ICD-10-CM) code. J Am Med Dir Assoc 17:675-677. https://doi.org/10.1016/j.jamda.2016.06.001

50. Batsis JA, Mackenzie TA, Lopez-Jimenez F, Bartels SJ (2015) Sarcopenia, sarcopenic obesity, and functional impairments in older adults: National Health and Nutrition Examination Surveys 1999-2004. Nutr Res 35:1031-1039. https://doi.org/10.1016/j. nutres.2015.09.003

51. Atkins JL, Whincup PH, Morris RW, Lennon LT, Papacosta O, Wannamethee SG (2014) Sarcopenic obesity and risk of cardiovascular disease and mortality: a population-based cohort study of older men. J Am Geriatr Soc 62:253-260. https://doi.org/10.1111/ jgs. 12652

52. Beaudart C, Zaaria M, Pasleau F, Reginster JY, Bruyere O (2017) Health outcomes of sarcopenia: a systematic review and metaanalysis. PLoS One 12:e169548. https://doi.org/10.1371/ journal.pone. 0169548

53. Lee J, Hong YP, Shin HJ, Lee W (2016) Associations of sarcopenia and sarcopenic obesity with metabolic syndrome considering both muscle mass and muscle strength. J Prev Med Public Health 49:35-44. https://doi.org/10.3961/jpmph.15.055

54. Verschueren S, Gielen E, O'Neill TW et al (2013) Sarcopenia and its relationship with bone mineral density in middle-aged and elderly European men. Osteoporos Int 24:87-98. https://doi.org/10. 1007/s00198-012-2057-z

55. Scott D, Hayes A, Sanders KM, Aitken D, Ebeling PR, Jones G (2014) Operational definitions of sarcopenia and their associations with 5-year changes in falls risk in community-dwelling middleaged and older adults. Osteoporos Int 25:187-193. https://doi.org/ $10.1007 / \mathrm{s} 00198-013-2431-5$ 
56. Scott D, de Courten B, Ebeling PR (2016) Sarcopenia: a potential cause and consequence of type 2 diabetes in Australia's ageing population? Med J Aust 205:329-333

57. Baumgartner RN, Wayne SJ, Waters DL, Janssen I, Gallagher D, Morley JE (2004) Sarcopenic obesity predicts instrumental activities of daily living disability in the elderly. Obes Res 12:19952004. https://doi.org/10.1038/oby.2004.250

58. Scott D, Seibel M, Cumming R, Naganathan V, Blyth F, Le Couteur DG, Handelsman DJ, Waite LM, Hirani V (2017) Sarcopenic obesity and its temporal associations with changes in bone mineral density, incident falls, and fractures in older men: the Concord Health and Ageing in Men Project. J Bone Miner Res 32: 575-583. https://doi.org/10.1002/jbmr.3016

59. Morley JE (2012) Sarcopenia in the elderly. Fam Pract 29(Suppl 1):i44-i48. https://doi.org/10.1093/fampra/cmr063

60. Hayashida I, Tanimoto Y, Takahashi Y, Kusabiraki T, Tamaki J (2014) Correlation between muscle strength and muscle mass, and their association with walking speed, in community-dwelling elderly Japanese individuals. PLoS One 9:e111810. https://doi.org/ 10.1371/journal.pone. 0111810

61. Delmonico MJ, Harris TB, Visser M et al (2009) Longitudinal study of muscle strength, quality, and adipose tissue infiltration. Am J Clin Nutr 90:1579-1585. https://doi.org/10.3945/ajcn.2009. 28047

62. Hughes VA, Frontera WR, Wood M, Evans WJ, Dallal GE, Roubenoff R, Fiatarone Singh MA (2001) Longitudinal muscle strength changes in older adults: influence of muscle mass, physical activity, and health. J Gerontol A Biol Sci Med Sci 56:B209B217

63. Scott D, Johansson J, McMillan LB, Ebeling PR, Nordstrom A, Nordstrom P (2018) Mid-calf skeletal muscle density and its associations with physical activity, bone health and incident 12month falls in older adults: the Healthy Ageing Initiative. Bone 120:446-451. https://doi.org/10.1016/j.bone.2018.12.004

64. Bean JF, Kiely DK, LaRose S, O’Neill E, Goldstein R, Frontera WR (2009) Increased velocity exercise specific to task training versus the National Institute on Aging's strength training program: changes in limb power and mobility. J Gerontol A Biol Sci Med Sci 64:983-991. https://doi.org/10.1093/gerona/glp056

65. Mithal A, Bonjour JP, Boonen S et al (2013) Impact of nutrition on muscle mass, strength, and performance in older adults. Osteoporos Int 24:1555-1566. https://doi.org/10.1007/s00198012-2236-y

66. Beaudart C, Rabenda V, Simmons M, Geerinck A, Araujo De Carvalho I, Reginster JY, Amuthavalli Thiyagarajan J, Bruyere O (2018) Effects of protein, essential amino acids, B-hydroxy Bmethylbutyrate, creatine, dehydroepiandrosterone and fatty acid supplementation on muscle mass, muscle strength and physical performance in older people aged 60 years and over. A systematic review of the literature. J Nutr Health Aging 22:117-130. https:// doi.org/10.1007/s12603-017-0934-Z

67. Devries MC, McGlory C, Bolster DR, Kamil A, Rahn M, Harkness L, Baker SK, Phillips SM (2018) Leucine, not total protein, content of a supplement is the primary determinant of muscle protein anabolic responses in healthy older women. $\mathrm{J}$ Nutr 148:1088-1095. https://doi.org/10.1093/jn/nxy091

68. Cermak NM, Res PT, de Groot LC, Saris WH, van Loon LJ (2012) Protein supplementation augments the adaptive response of skeletal muscle to resistance-type exercise training: a metaanalysis. Am J Clin Nutr 96:1454-1464. https://doi.org/10.3945/ ajen.112.037556

69. Rodacki CL, Rodacki AL, Pereira G, Naliwaiko K, Coelho I, Pequito D, Fernandes LC (2012) Fish-oil supplementation enhances the effects of strength training in elderly women. Am J Clin Nutr 95:428-436. https://doi.org/10.3945/ajcn.111.021915
70. Da Boit M, Sibson R, Sivasubramaniam S et al (2017) Sex differences in the effect of fish-oil supplementation on the adaptive response to resistance exercise training in older people: a randomized controlled trial. Am J Clin Nutr 105:151-158. https://doi.org/ 10.3945/ajen.116.140780

71. Pinto CL, Botelho PB, Carneiro JA, Mota JF (2016) Impact of creatine supplementation in combination with resistance training on lean mass in the elderly. J Cachexia Sarcopenia Muscle 7:413421. https://doi.org/10.1002/jcsm.12094

72. Camporez JP, Petersen MC, Abudukadier A, Moreira GV, Jurczak MJ, Friedman G, Haqq CM, Petersen KF, Shulman GI (2016) Anti-myostatin antibody increases muscle mass and strength and improves insulin sensitivity in old mice. Proc Natl Acad Sci U S A 113:2212-2217. https://doi.org/10.1073/pnas.1525795113

73. Rooks D, Praestgaard J, Hariry S, Laurent D, Petricoul O, Perry RG, Lach-Trifilieff E, Roubenoff R (2017) Treatment of sarcopenia with bimagrumab: results from a phase II, randomized, controlled, proof-of-concept study. J Am Geriatr Soc 65:19881995. https://doi.org/10.1111/jgs.14927

74. Osteoarthritis Research Society International (2013) What is osteoarthritis? Osteoarthritis Research Society International. https:// www.oarsi.org/what-osteoarthritis. Accessed 12 Feb 2019

75. Steultjens MP, Dekker J, van Baar ME, Oostendorp RA, Bijlsma JW (2000) Range of joint motion and disability in patients with osteoarthritis of the knee or hip. Rheumatology (Oxford) 39:955961

76. Neogi T (2013) The epidemiology and impact of pain in osteoarthritis. Osteoarthr Cartil 21:1145-1153. https://doi.org/10.1016/j. joca.2013.03.018

77. Laslett LL, Quinn SJ, Winzenberg TM, Sanderson K, Cicuttini F, Jones $\mathrm{G}$ (2012) A prospective study of the impact of musculoskeletal pain and radiographic osteoarthritis on health related quality of life in community dwelling older people. BMC Musculoskelet Disord 13:168. https://doi.org/10.1186/1471-2474-13-168

78. Hootman JM, Helmick CG, Barbour KE, Theis KA, Boring MA (2016) Updated projected prevalence of self-reported doctor-diagnosed arthritis and arthritis-attributable activity limitation among US adults, 2015-2040. Arthritis Rheum 68:1582-1587. https:// doi.org/10.1002/art.39692

79. Srikanth VK, Fryer JL, Zhai G, Winzenberg TM, Hosmer D, Jones G (2005) A meta-analysis of sex differences prevalence, incidence and severity of osteoarthritis. Osteoarthr Cartil 13: 769-781. https://doi.org/10.1016/j.joca.2005.04.014

80. Zasadzka E, Borowicz AM, Roszak M, Pawlaczyk M (2015) Assessment of the risk of falling with the use of timed up and go test in the elderly with lower extremity osteoarthritis. Clin Interv Aging 10:1289-1298. https://doi.org/10.2147/cia.s86001

81. Hochberg MC, Altman RD, April KT, Benkhalti M, Guyatt G, McGowan J, Towheed T, Welch V, Wells G, Tugwell P (2012) American College of Rheumatology 2012 recommendations for the use of nonpharmacologic and pharmacologic therapies in osteoarthritis of the hand, hip, and knee. Arthritis Care Res 64:465474

82. Melanson KJ (2007) Diet, nutrition and osteoarthritis. Am J Lifestyle Med 1:260-263. https://doi.org/10.1177/ 1559827607302033

83. Miller GD, Nicklas BJ, Davis C, Loeser RF, Lenchik L, Messier SP (2006) Intensive weight loss program improves physical function in older obese adults with knee osteoarthritis. Obesity (Silver Spring, Md) 14:1219-1230. https://doi.org/10.1038/oby.2006.139

84. Fransen M, McConnell S, Harmer AR, Van der Esch M, Simic M, Bennell KL (2015) Exercise for osteoarthritis of the knee: a Cochrane systematic review. Br J Sports Med 49:1554-1557. https://doi.org/10.1136/bjsports-2015-095424 
85. (2018) Falls prevention facts. National Council on Aging. https:// www.ncoa.org/news/resources-for-reporters/get-the-facts/fallsprevention-facts/. Accessed 12 Feb 2019

86. Fraix M (2012) Role of the musculoskeletal system and the prevention of falls. J Am Osteopath Assoc 112:17-21

87. Patel KV, Phelan EA, Leveille SG, Lamb SE, Missikpode C, Wallace RB, Guralnik JM, Turk DC (2014) High prevalence of falls, fear of falling, and impaired balance in older adults with pain in the United States: findings from the 2011 National Health and Aging Trends Study. J Am Geriatr Soc 62:1844-1852. https://doi. org/10.1111/jgs. 13072

88. Albert SM, King J, Boudreau R, Prasad T, Lin CJ, Newman AB (2014) Primary prevention of falls: effectiveness of a statewide program. Am J Public Health 104:e77-e84. https://doi.org/10. 2105/ajph.2013.301829

89. Clemson L, Fiatarone Singh MA, Bundy A, Cumming RG, Manollaras K, O'Loughlin P, Black D (2012) Integration of balance and strength training into daily life activity to reduce rate of falls in older people (the LiFE study): randomised parallel trial. BMJ 345:e4547. https://doi.org/10.1136/bmj.e4547

90. Sherrington C, Michaleff ZA, Fairhall N, Paul SS, Tiedemann A, Whitney J, Cumming RG, Herbert RD, Close JCT, Lord SR (2017) Exercise to prevent falls in older adults: an updated systematic review and meta-analysis. Br J Sports Med 51:1750-1758. https://doi.org/10.1136/bjsports-2016-096547

91. de Souto BP, Rolland Y, Vellas B, Maltais M (2018) Association of long-term exercise training with risk of falls, fractures, hospitalizations, and mortality in older adults: a systematic review and meta-analysis. JAMA Intern Med 179:394. https://doi.org/10. 1001/jamainternmed.2018.5406

92. Wolfson L, Whipple R, Derby C, Judge J, King M, Amerman P, Schmidt J, Smyers D (1996) Balance and strength training in older adults: intervention gains and Tai Chi maintenance. J Am Geriatr Soc 44:498-506

93. Moyer VA (2012) Prevention of falls in community-dwelling older adults: U.S. Preventive Services Task Force recommendation statement. Ann Intern Med 157:197-204. https://doi.org/10. 7326/0003-4819-157-3-201208070-00462

94. Grossman DC, Curry SJ, Owens DK et al (2018) Interventions to prevent falls in community-dwelling older adults: US Preventive Services Task Force recommendation statement. JAMA 319: 1696-1704. https://doi.org/10.1001/jama.2018.3097
95. (2019) Evidence-based falls prevention programs. National Council on Aging. https://www.ncoa.org/healthy-aging/fallsprevention/falls-prevention-programs-for-older-adults-2/. Accessed 9 Apr 2019

96. Holick MF, Binkley NC, Bischoff-Ferrari HA, Gordon CM, Hanley DA, Heaney RP, Murad MH, Weaver CM (2011) Evaluation, treatment, and prevention of vitamin D deficiency: an Endocrine Society clinical practice guideline. J Clin Endocrinol Metab 96:1911-1930. https://doi.org/10.1210/jc. 2011-0385

97. (2018) Calcium and vitamin D: what you need to know. National Osteoporosis Foundation. https://www.nof.org/patients/treatment/ calciumvitamin-d/. Accessed 18 Mar 2019

98. Balzer K, Bremer M, Schramm S, Luhmann D, Raspe H (2012) Falls prevention for the elderly. GMS Health Technol Assess 8: Doc01. https://doi.org/10.3205/hta000099

99. Springer KW, Mouzon DM (2011) "Macho men" and preventive health care: implications for older men in different social classes. J Health Soc Behav 52:212-227. https://doi.org/10.1177/ 0022146510393972

100. Milligan C, Neary D, Payne S, Hanratty B, Irwin P, Dowrick C (2016) Older men and social activity: a scoping review of men's sheds and other gendered interventions. Ageing Soc 36:895-923

101. Bredland EL, Soderstrom S, Vik K (2018) Challenges and motivators to physical activity faced by retired men when ageing: a qualitative study. BMC Public Health 18:627. https://doi.org/10. 1186/s12889-018-5517-3

102. Moschny A, Platen P, Klaassen-Mielke R, Trampisch U, Hinrichs $\mathrm{T}$ (2011) Barriers to physical activity in older adults in Germany: a cross-sectional study. Int J Behav Nutr Phys Act 8:121. https://doi. org/10.1186/1479-5868-8-121

103. Simmonds BAJ, Hannam KJ, Fox KR, Tobias JH (2016) An exploration of barriers and facilitators to older adults' participation in higher impact physical activity and bone health: a qualitative study. Osteoporos Int 27:979-987. https://doi.org/10.1007/ s00198-015-3376-7

104. Ebeling PR, Daly RM, Kerr DA, Kimlin MG (2013) An evidenceinformed strategy to prevent osteoporosis in Australia. Med J Aust 198:90-91

Publisher's note Springer Nature remains neutral with regard to jurisdictional claims in published maps and institutional affiliations. 